\title{
Treatment of diabetes in children (Review)
}

\author{
YI-QING GAO, MIN GAO and YING XUE \\ Department of Endocrinology, Xuzhou Children's Hospital, Xuzhou, Jiangsu 221002, P.R. China
}

Received December 3, 2015; Accepted January 29, 2016

DOI: $10.3892 / \mathrm{etm} .2016 .3039$

\begin{abstract}
Type 1 diabetes mellitus (T1D) and type 2 diabetes (T2D) mellitus are on the increase in children and adolescents. An increase in T2D is linked to the increasing rates of obesity in children. Usually, in both children and adults, T1D is treated with insulin while T2D is treated with metformin. There are other classes of drugs that are under assessment for their safety and efficacy in relation to pediatric patients. Most of these new drugs, however, have not been studied in children. Thus, the repertoire of drugs that are available to treat diabetes in children is limited. In this review, we outline the current pathology and treatment and future therapies of T1D mellitus and T2D mellitus in children.
\end{abstract}

\section{Contents}

\author{
1. Introduction \\ 2. Pathology \\ 3. Diagnosis \\ 4. Primary treatment of type 2 diabetes \\ 5. Insulin treatment in type 2 diabetes \\ 6. Alternative drug treatments in childhood type 2 \\ diabetes \\ 7. Treatment of type 1 diabetes \\ 8. Lifestyle modifications \\ 9. Investigational treatments \\ 10. Conclusion
}

\section{Introduction}

Type 2 diabetes (T2D) mellitus has been on the increase in young individuals, and is correlated with the increase in childhood obesity. A survey conducted in 2008 showed that the prevalence of T2D increased from 9 to $23 \%$ over the span of 8 years, between 2000 and 2008 (1). Rates of T2D are also

Correspondence to: Dr Ying Xue, Department of Endocrinology, Xuzhou Children's Hospital, 18 Sudibei Road, Xuzhou, Jiangsu 221002, P.R. China

E-mail: xueying96@yeah.net

Key words: metformin, type 2 diabetes, type 1 diabetes dependent on ethnicity as the greatest increase in childhood T2D was predominantly in non-white ethnic groups. The incidence of T2D in individuals of European, African-American and American-Indian ethnicity was 3, 15.7 and 49.4 out of 100,000 individuals aged 10-19 years, respectively. In addition, more females were diagnosed with T2D than males (2). Type 1 diabetes (T1D) mellitus, similar to T2D, is also on the increase worldwide. The rates of T1D are the highest in Scandinavian countries, the UK, the USA, Canada and Australia. In Finland, the incidence of T1D is $57 / 100,000$ children while the incidence of T1D in other western countries is approximately 20/100,000 children. Asian and African countries have lower rates of T1D. Despite the already high rates in European countries, the incidence of T1D is actually on the increase across Europe, at 3.9\% annually in children. Asian and African countries have lower rates of T1D. Despite the already high rates in European countries, the incidence of T1D is on the increase across Europe, $3.9 \%$ year in children (3). In addition, T1D has increased in the US at a rate of $21 \%$ in the 8 years between 2001 and 2009. In the present review, we provide the current guidelines on treating T1D and T2D mellitus (4).

\section{Pathology}

Under non-pathological conditions, an increase in blood glucose triggers a secretion of insulin from the $\beta$ cells of the pancreas. The hormone glucagon is secreted by the $\alpha$ cells of the pancreas, which activates gluconeogenesis, thereby preventing hypoglycemia during times when no food is being digested. T2D mellitus develops when there is a discrepancy in glucose metabolism and storage. The pathology behind T2D involves a decrease in peripheral tissue sensitivity to insulin as well as decreased insulin secretion from the $\beta$ cells. When the tissues become less sensitive to insulin, the $\beta$ cells start to increase insulin secretion. When the $\beta$ cells start to overcompensate in this manner, it leads to overburdening of work on the $\beta$ cells. Overworked $\beta$ cells start to reduce their functions, which leads to an eventual decrease in insulin secretion. This leads to the phenomenon of glucose intolerance, which impairs the secretion of glucagon. When glucagon no longer fulfills its regular function, the glycemic state of a patient becomes exacerbated and leads to an aggravation of diabetic pathology $(5,6)$.

Childhood obesity and increased body fat are correlated with insulin resistance. The mechanism behind the way obesity affects T2D is well known. Obesity rates have increased considerably over the past 40 years. In 1980, the childhood obesity rates were $6.5 \%$, which increased to $16.9 \%$ in 2008 (7). 
The percentage of overweight and obese children and adolescents, aged 2-19 years, is $\sim 33 \%$. Overweight or obese children are more at risk for developing T2D as well as other diseases including cardiovascular disease. Due to the fact that overweight or obese children are more at risk for other diseases and complications, it is imperative to prevent a serious disease such as T2D (8).

T1D is a disorder that affects genetically susceptible individuals, but may also occur in individuals with no genetic predisposition. T1D is an autoimmune disorder, leading to a loss of pancreatic $\beta$ cells. T1D occurs due to the presence of autoantibodies that destroy proteins that form a $\beta$ cell. The most common antibody in patients with T1D is directed towards a $\beta$-cell enzyme, glutamic acid decarboxylase. Patients with T1D may also have anti-insulin antibodies. As the number of $\beta$ cells decreases, insulin concentration concurrently decreases until there is no longer insulin available to regulate glucose levels. However, hyperglycemia does not develop until $80-90 \%$ of the cells are destroyed. If the condition goes untreated, diabetic ketosis may develop. One of the ways that T1D is activated in individuals that are genetically susceptible is through viral infection, which may stimulate the production of antibodies towards the virus, which contains similar antigens to $\beta$ cells. The incidence of T1D is increased in patients with other autoimmune diseases such as Graves and Addison disease $(7,9)$.

\section{Diagnosis}

Diagnosing diabetes in children is difficult as there may be confusion between T1D and T2D. Historically, children with diabetes were diagnosed with T1D. However, the rise in obesity and the consequent rise of T2D in children have obscured the diagnosis. Approximately $25 \%$ of children with T1D are overweight or obese. There are guidelines to determine, and differentiate, between the two diagnoses in children (Table I). T2D diagnosis in youth is normally dependent on glucose concentrations and symptoms such as excess urine, vision problems, excess thirst, weight loss and ketonuria. A definite diagnosis of T2D is made when these symptoms are also complemented with a $>200 \mathrm{mg} / \mathrm{dl}$ random glucose concentration or a $>126 \mathrm{mg} / \mathrm{dl}$ fasting glucose concentration. Children with a high body mass index (BMI), a family history of diabetes, antibodies that denoted insulin resistance and other issues such as hypertension are high-risk for T2D. The age at diagnosis for T2D in the youth is generally at puberty; and rarely presents at $<10$ years. T2D usually presents with diabetic ketoacidosis in 5-20\% of the cases (10).

The age at diagnosis for T1D is much lower than that for $\mathrm{T} 2 \mathrm{D}$, at the age of 6 months to 18 years. The symptoms that usually present with T1D range from weight loss, thyroid autoimmunity and celiac disease. Approximately $25 \%$ of the time, T1D cases presented with diabetic ketoacidosis. Similar to T2D, T1D diagnosis is made through blood glucose tests. A fasting blood glucose test can be performed, although they are often not reliable. In that case, an oral glucose tolerance test may be conducted. Such a test involves the patient ingesting a specific glucose solution and then a glucose test is performed after $2 \mathrm{~h}$. Another test that can be performed is the glycated hemoglobin test (A1C test) which analyzes blood glucose levels over the previous few months as opposed to
Table I. Features that characterize type 1 and type 2 diabetes mellitus.

\begin{tabular}{lcc}
\hline Characteristics & T1D & T2D \\
\hline $\begin{array}{l}\text { Date of } \\
\text { presentation }\end{array}$ & 6 months-18 years & 10 years + \\
$\begin{array}{l}\text { Length of } \\
\text { pathology }\end{array}$ & Sudden & Gradual \\
Ketoacidosis & Normal & Rare \\
Body weight & Normal & Obese (often) \\
$\begin{array}{l}\text { Insulin levels } \\
\text { Autoantibodies }\end{array}$ & Few & Normal, greater or fewer \\
Incidence & Normal & Not present \\
& (USA) & $90-95 \%$ of cases \\
& (USA)
\end{tabular}

T1D, type 1 diabetes; T2D, type 2 diabetes.

one particular time point. This test assesses the percentage of hemoglobin, to which glucose is bound, and a high percentage indicates diabetes. Once diabetes is diagnosed, an antibody test would be administered, which could be used differentiate between a T1D diagnosis and a T2D diagnosis $(10,11)$.

\section{Primary treatment of type 2 diabetes}

Children with T2D are almost always started on metformin. Metformin is a drug that is classified as a biguanide. This drug functions by reducing glucose production and by activating glucose uptake in peripheral tissues. Metformin is administered in children at a $500 \mathrm{mg}$ dose, and is ingested at meal times daily. The dose is increased by $500 \mathrm{mg}$ each week until the dose equals $2,000 \mathrm{mg}$. There are some adverse events associated with the use of metformin including gastrointestinal problems (abdominal pain and diarrhea), which may result in a patient not reaching optimal dose of metformin. In some rare instances, lactic acidosis and renal dysfunction can occur in individuals taking metformin (12). Metformin reduces glycated hemoglobin levels to $2 \%$ and also aids in weight loss. Clinical trials have shown that the use of metformin is safe for T2D pediatric patients. Another study found that in patients aged 10-17, metformin and $4 \mathrm{mg}$ rosiglitazone was a superior therapy for T2D than metformin alone $(11,13)$.

\section{Insulin treatment in type 2 diabetes}

Insulin may also be used in treating childhood T2D. Exogenous insulin helps maintain glucose homeostasis by aiding muscle and adipose tissue uptake excess glucose and reduce glucose production (14). Caveats to using insulin include weight gain, hypoglycemia and increased insulin. There are certain insulin types that are used for pediatric patients, such as glulisine, detemir, glargine, hagedorn, aspart, regular and neutral protamine (15). However, the most successful treatment is the administration of a single dose of long-acting insulin at bedtime. Although the clinical guidelines state that insulin should be used as a first-line treatment in $\mathrm{T} 2 \mathrm{D}$ pediatric 
patients that are ketotic, some clinicians choose not to due to the potentially undesirable effects. Administration of insulin early in the disease pathogenesis is good practice as it leads to a normalization of glucose $(11,16)$.

\section{Alternative drug treatments in childhood type 2 diabetes}

Another class of drugs that is useful in the decrease of glucose concentrations is thiazolidinediones. They function by increasing insulin sensitivity in areas of the body including liver, muscles and adipose tissue. These drugs also decrease glucose synthesis of the liver. However, thiazolidinediones are not approved for use in children. In adults, thiazolidinediones decrease glycated hemoglobin to $1 \%$ (17). Some of the drugs in this class include rosiglitazone and pioglitazone, which have been studied in clinical trials. Another class of drugs that can be used to treat T2D but are not approved for use in children is meglitinides. Two drugs included in this class are repaglinide and nateglinide, which function by stimulating insulin from the pancreas. Complications that can result from meglitinides include hypoglycemia, upper respiratory tract infection, diarrhea and headaches (18).

Sulfonylureas can also be used to treat diabetes and function by activating the $\beta$ cells to secrete insulin. Although sulfonylureas are not generally used for the pediatric population, they have been known to be safe for children (19). The specific types of sulfonylureas that have been studied in children are glimepiride and glipizide. The caveats of sulfonylureas are usually weight gain and hypoglycemia. Clinical studies using glimepride in children showed it was equally effective at treating T2D as metformin. Sulfonylureas in adults also reduced glycated hemoglobin levels to $1.25 \%$ in adults (20). The use of sulfonylureas in other conditions such as maturity-onset diabetes of the young has been investigated Long-term use of sulfonylureas enhanced insulin levels by approximately $68 \%(11,21)$.

$\alpha$-glucosidase inhibitors such as acarbose and miglitol can be used to treat $\mathrm{T} 2 \mathrm{D}$ by reducing the absorption of carbohydrates in the distal small intestine, which reduces serum glucose. While $\alpha$-glucosidase inhibitors can decrease glycated hemoglobin levels, their use in children has not been sufficiently investigated. Common complications from these drugs are diarrhea and abdominal cramps. In a double-blind randomized trial, it was found that acarbose may be useful for the paediatric population with $\mathrm{T} 2 \mathrm{D}$, although at a significant cost because of gastrointestinal side effects. Glucagon-like peptide-1 (GLP-1) agonists are another class of T2D drugs. GLP-1 is a hormone released from the gut in response to digestion of meals and functions in insulin biosynthesis. Similar to other T2D drugs, these agonists have yet to be approved for pediatric patients. Exenatide is a GLP-1 agonist, which has been studied in the youth population for its effect on T2D. Previously, $5 \mathrm{mcg}$ exenatide was administered twice a day in obese youth aged 12-19 years, which led to a significant decrease in BMI $(21,22)$.

\section{Treatment of type 1 diabetes}

Unlike children diagnosed with T2D, children with T1D need insulin treatment to survive. Oral insulin is not an option

\section{Blood glucose levels (random) $>250 \mathrm{mg} / \mathrm{dl}$}

Glycated hemaglobin $>9 \%$

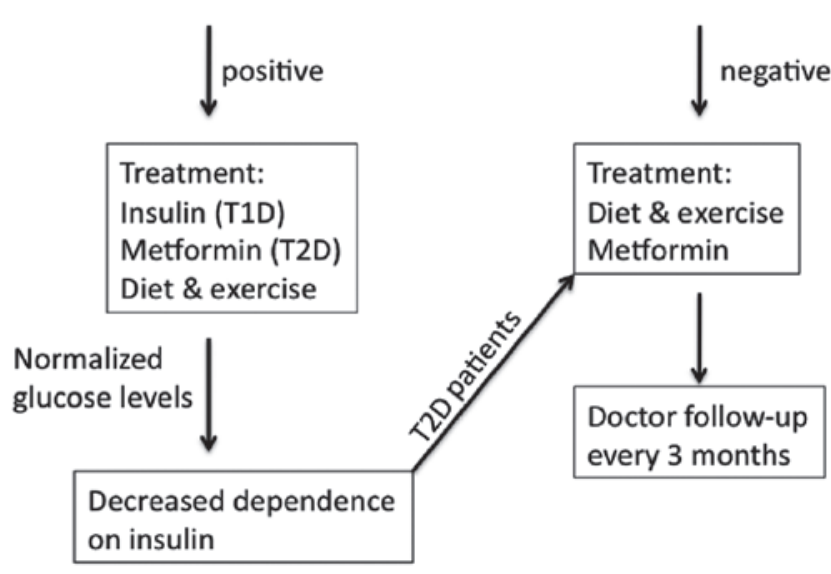

Figure 1. Diagnosis and treatment plan for pediatrics patients diagnosed with type 1 diabetes (T1D) or type 2 diabetes (T2D).

for patients with diabetes as gastric enzymes impede oral insulin (23).

There are many types of insulin that are available for the treatment of T1D. Rapid-acting insulin, such as lispro and aspart, begins functioning within 15 min post-injection. Another type of insulin is short-acting insulin, which begins working approximately $30 \mathrm{~min}$ post-injection and reaches peak performance within 2-4 h. Long-acting insulin is another type of insulin, which does not have a peak but provides use for 20-25 h. Some examples of long-acting insulin include glargine and detemire. Intermediate-acting insulin is another type of insulin that starts to function at $30 \mathrm{~min}$ to $1 \mathrm{~h}$ and reaches its peak at 4-6 h. An example of this type of insulin is NPH insulin. When prescribing insulin, doctors take into account a child's age and his/her needs and therefore, may prescribe a mixture of these insulin types. Insulin is delivered using a fine needle and syringe or pen, which looks similar to an ink pen but is instead filled with insulin. Many children can also use an insulin pump, which is generally the size of a cell phone. A tube connects the insulin to a catheter that is inserted in the abdomen. The pump can be adjusted to deliver the appropriate amount of insulin depending on glucose level (24).

Insulin is used in the majority of cases of children with T1D. However, clinical trials have been conducted to determine the effectiveness of other drugs for treatment. In pediatric patients with T1D, 4 mg glimepiride was administered to 40 children in a randomized clinical trial. However, the investigators found no difference between the groups with regard to weight, blood pressure, insulin dose, serum glucose, hypoglycemia and serum lipids. The drug was found to be safe for the patients, although further research is essential to determine whether a higher dose may actually have a beneficial effect. Exenatide, a GLP-1 agonist, was investigated as an adjunctive treatment to insulin in children with T1D (25). Eight adolescents, aged 13-22 years, were examined and administered two doses of exenatide or insulin. Exenatide was found to decrease hyperglycemia but did not suppress glucose. 
The investigators of that study concluded that exenatide may be used as an effective adjunctive treatment to insulin for the treatment of T1D.

Another class of drugs is amylin analogs, an example of which is pramlintide. Amylin is a hormone that is known to inhibit glucagon secretion, cause a delay in gastric emptying and increase satiety. In pediatric patients with T1D, pramlintide was studied at a dose of $15-30 \mathrm{mcg}$. Pramlintide was shown to reduce glucose levels with minimal complications. Previous findings showed that when given to youth with T1D, pramlintide reduced glycated hemoglobin, BMI and total insulin dose. Thus, amylin analog pramlintide is a promising drug that can be used in the treatment of diabetes $(11,26)$.

\section{Lifestyle modifications}

In children with T1D and T2D, lifestyle modifications are an important part of the treatment. Lifestyle modifications include $\geq 1$ h of vigorous physical activity and maintaining a healthy BMI (18.5-24.9). In children with T2D, lifestyle modifications are paramount and a cornerstone for treatment of the disease (27). However, only $10 \%$ of children achieve their lifestyle modification aims. There are many reasons for this lack of success, including peer pressure for unhealthy eating and that many patients do not understand the importance of a diet. The prescribed amount of physical activity a day is $\geq 60$ min. In addition, other lifestyle modifications include decreasing screen-time such as using a television or computer, to $<2$ h/day (28).

Nutritional change is another necessary lifestyle modification that is advised to children with T1D and T2D. Normal dietary recommendations involve consumption of regular meals and healthy snacks, decreased portion sizes, consumption of calorie-free beverages such as water, and an increase in the consumption of fruits and vegetables. However, there is no 'diabetes diet'. A good diet should include foods that are high in nutrients and low in fat and calories, and consumption of fewer animal products and sweets. High-fat foods are especially of poor quality because fat slows digestion leading to a spike in blood sugar levels several hours after meal consumption (27-29).

\section{Investigational treatments}

Besides the abovementioned clinical trials for drugs that are being investigated for their treatment potential for diabetes, other treatments have been considered. The first of these treatments is pancreas transplant, which, if successful, lead to a child no longer having to inject insulin. However, these transplants are not always successful and constitute a high-risk factor. In addition, with a pancreas transplant, the patient always require immune-suppressing drugs to preven organ rejection. Due to the issues with pancreas transplant, it is limited to individuals with kidney failure. The second treatment is islet cell transplantation, which provides new $\beta$ cells from a donor pancreas. New techniques and improved drugs are now in use to prevent islet cell rejection. However, this transplant requires immune-suppressing medication. In the case of T1D patients, the body may occasionally destroy transplanted islet cells, just as it did the original cells (30-31).

\section{Conclusion}

Diabetes has surfaced as a serious problem in children in recent few decades. There are guidelines in place to diagnose and treat children with T1D and T2D (Fig. 1). T1D mellitus is an autoimmune disease that occurs in children that may be genetically susceptible. Children with T1D develop antibodies to $\beta$-cell components, which leads to an eventual decrease in insulin production. Children with T2D develop the problem for a number of reasons, one of which is an increase in peripheral fat deposits that desensitize tissues to insulin and decrease insulin production. The primary way to treat T1D is to administer insulin while metformin is used to treat T2D. Other classes of drugs, such as thiazolidiniones, sulfonylureas, meglitinides, $\alpha$-glucosidase inhibitors, GLP-1 agonists and amylin analogs, have emerged as potential alternatives to insulin and metformin. However, these drugs have not been studied in children and therefore, are not currently in use for the pediatric population. Lifestyle modifications are also extremely important for proper management of the two types of diabetes. Lifestyle modifications include physical activity and nutrition management. Due to the increasing prevalence of T1D and T2D in children, these new drugs and transplants need to be further investigated to determine their safety and effect on children.

\section{References}

1. May AL, Kuklina EV and Yoon PW: Prevalence of cardiovascular disease risk factors among US adolescents, 1999-2008. Pediatrics 129: 1035-1041, 2012.

2. McBean AM, Li S, Gilbertson DT and Collins AJ: Differences in diabetes prevalence, incidence, and mortality among the elderly of four racial/ethnic groups: Whites, blacks, hispanics, and asians. Diabetes Care 27: 2317-2324, 2004.

3. Onkamo $P$, Väänänen $S$, Karvonen $M$ and Tuomilehto $J$ : Worldwide increase in incidence of Type I diabetes - the analysis of the data on published incidence trends. Diabetologia 42: 1395-1403, 1999.

4. Patterson C, Guariguata L, Dahlquist G, Soltész G, Ogle G and Silink M: Diabetes in the young - a global view and worldwide estimates of numbers of children with type 1 diabetes. Diabetes Res Clin Pract 103: 161-175, 2014.

5. Klöppel G, Löhr M, Habich K, Oberholzer M and Heitz PU: Islet pathology and the pathogenesis of type 1 and type 2 diabetes mellitus revisited. Surv Synth Pathol Res 4: 110-125, 1985.

6. Zammitt NN and Frier BM: Hypoglycemia in type 2 diabetes: Pathophysiology, frequency, and effects of different treatment modalities. Diabetes Care 28: 2948-2961, 2005.

7. Hannon TS, Rao G and Arslanian SA: Childhood obesity and type 2 diabetes mellitus. Pediatrics 116: 473-480, 2005.

8. Ogden CL, Flegal KM, Carroll MD and Johnson CL: Prevalence and trends in overweight among US children and adolescents, 1999-2000. JAMA 288: 1728-1732, 2002.

9. Tuomilehto J, Zimmet P, Mackay IR, Koskela P, Vidgren G, Toivanen L, Tuomilehto-Wolf E, Kohtamäki K, Stengård J and Rowley MJ: Antibodies to glutamic acid decarboxylase as predictors of insulin-dependent diabetes mellitus before clinical onset of disease. Lancet 343: 1383-1385, 1994.

10. Association AD; American Diabetes Association: Type 2 diabetes in children and adolescents. Pediatrics 105: 671-680, 2000.

11. Scheen AJ: Clinical pharmacokinetics of metformin. Clin Pharmacokinet 30: 359-371, 1996.

12. Aronoff SL, Berkowitz K, Shreiner B and Want L: Glucose metabolism and regulation: beyond insulin and glucagon. Diab Spectr 17: 183-190, 2004.

13. Miles HL and Acerini CL: Insulin analog preparations and their use in children and adolescents with type 1 diabetes mellitus. Paediatr Drugs 10: 163-176, 2008. 
14. Davidson MB, Castellanos M, Kain D and Duran P: The effect of self monitoring of blood glucose concentrations on glycated hemoglobin levels in diabetic patients not taking insulin: a blinded, randomized trial. Am J Med 118: 422-425, 2005.

15. Ludwig DS and Ebbeling CB: Type 2 diabetes mellitus in children: primary care and public health considerations. JAMA 286: 1427-1430, 2001

16. Patel A, MacMahon S, Chalmers J, Billot L, Woodward M, Marre M, Cooper M, Glasziou P, Grobbee D, Hamet P and Harrap S: Intensive blood glucose control and vascular outcomes in patients with type 2 diabetes. N Engl J Med 358: 2560-2572, 2008.

17. Carino GP and Mathiowitz E: Oral insulin delivery. Adv Drug Deliv Rev 35: 249-257, 1999.

18. Gutniak M, Ørkov C, Holst JJ, Ahrén B and Efendić S: Antidiabetogenic effect of glucagon-like peptide-1 (7-36) amide in normal subjects and patients with diabetes mellitus. N Engl J Med 326: 1316-1322, 1992.

19. Diabetes Prevention Program Research Group. Reduction in the incidence of type 2 diabetes with lifestyle intervention or metformin. N Engl J Med 346: 393-403, 2002

20. Goran MI, Bergman RN, Avila Q, Watkins M, Ball GD, Shaibi GQ, Weigensberg MJ and Cruz ML: Impaired glucose tolerance and reduced $\beta$-cell function in overweight Latino children with a positive family history for type 2 diabetes. J Clin Endocrinol Metab 89: 207-212, 2004.

21. Jones KL, Arslanian S, Peterokova VA, Park JS and Tomlinson MJ: Effect of metformin in pediatric patients with type 2 diabetes: A randomized controlled trial. Diabetes Care 25: 89-94, 2002

22. Ehtisham S, Barrett TG and Shaw NJ: Type 2 diabetes mellitus in UK children - an emerging problem. Diabet Med 17: 867-871, 2000

23. Bandyopadhyay GK, Yu JG, Ofrecio J and Olefsky JM: Increased malonyl-CoA levels in muscle from obese and type 2 diabetic subjects lead to decreased fatty acid oxidation and increased lipogenesis; thiazolidinedione treatment reverses these defects. Diabetes 55: 2277-2285, 2006.
24. Pearson ER, Flechtner I, Njølstad PR, Malecki MT, Flanagan SE, Larkin B, Ashcroft FM, Klimes I, Codner E, Iotova V, et al; Neonatal Diabetes International Collaborative Group: Switching from insulin to oral sulfonylureas in patients with diabetes due to Kir6.2 mutations. N Engl J Med 355: 467-477, 2006.

25. Krentz AJ and Bailey CJ: Oral antidiabetic agents: Current role in type 2 diabetes mellitus. Drugs 65: 385-411, 2005.

26. Atkinson MA and Eisenbarth GS: Type 1 diabetes: New perspectives on disease pathogenesis and treatment. Lancet 358: 221-229, 2001.

27. Shapiro AM, Lakey JR, Ryan EA, Korbutt GS, Toth E, Warnock GL, Kneteman NM and Rajotte RV: Islet transplantation in seven patients with type 1 diabetes mellitus using a glucocorticoid-free immunosuppressive regimen. N Engl J Med 343: 230-238, 2000

28. Tuomilehto J, Lindström J, Eriksson JG, Valle TT, Hämäläinen H, Ilanne-Parikka P, Keinänen-Kiukaanniemi S, Laakso M, Louheranta A, Rastas M, et al; Finnish Diabetes Prevention Study Group: Prevention of type 2 diabetes mellitus by changes in lifestyle among subjects with impaired glucose tolerance. N Engl J Med 344: 1343-1350, 2001.

29. Sone H, Katagiri A, Ishibashi S, Abe R, Saito Y, Murase T, Yamashita H, Yajima Y, Ito H, Ohashi Y, et al: Effects of lifestyle modifications on patients with type 2 diabetes: the Japan Diabetes Complications Study (JDCS) study design, baseline analysis and three year-interim report. Horm Metab Res 34: 509-515, 2002.

30. Fioretto P, Steffes MW, Sutherland DE, Goetz FC and Mauer M Reversal of lesions of diabetic nephropathy after pancreas transplantation. N Engl J Med 339: 69-75, 1998.

31. Onge ES, Miller SA, Motycka C and DeBerry A: A review of the treatment of type 2 diabetes in children. J Pediatr Pharmacol Ther 20: 4-16, 2015. 